\title{
OXIDATIVE STRESS IN PRE-ECLAMPSIA- A STUDY ON CORRELATION BETWEEN MALONDIALDEHYDE AND LIPID PROFILE FROM MATERNAL AND CORD BLOOD
}

\author{
Rina Kumari ${ }^{1}$, Gajendra Kumar², Niru Chhetri ${ }^{3}$, Rajni ${ }^{4}$, Gorachand Bhattacharya ${ }^{5}$ \\ ${ }^{1}$ Assistant Professor, Department of Biochemistry, MGM Medical College and LSK Hospital, Kishanganj, Bihar. \\ ${ }^{2}$ Assistant Professor, Department of Otorhinolaryngology, MGM Medical College and LSK Hospital, Kishanganj, Bihar. \\ ${ }^{3}$ Associate Professor, Department of Biochemistry, MGM Medical College and LSK Hospital, Kishanganj, Bihar. \\ ${ }^{4}$ Professor, Department of Biochemistry, MGM Medical College and LSK Hospital, Kishanganj, Bihar. \\ 5Professor, Department of Biochemistry, Jagannath Gupta Institute of Medical Sciences and Hospitals, Kolkata.
}

\section{ABSTRACT}

\section{BACKGROUND}

Pre-eclampsia is a complex multisystem disorder that occurs during pregnancy as a complication. This is associated with hypertension and the blood pressure is either $140 / 90 \mathrm{mmHg}$ or more and in addition proteinuria. Incidence of pre-eclampsia occurs between $3 \%$ and $10 \%$ of pregnancies and the pathogenic characteristics are vasospasm, increased peripheral vascular resistance and reduced organ perfusion. Exact cause of pre-eclampsia is still unexplored, but improper placentation is an important factor, and among other causes generation of free radicals leading to oxidative stress is thought to be the prime cause.

Oxidative stress results in damage to the biomolecules with generation of reactive oxygen species, and since the lipid peroxidation products play major roles in generation of free radicals our objective was to establish a correlation between lipid profile and an important lipid peroxidation intermediate like malondialdehyde in maternal and cord blood of women with preeclampsia.

\section{MATERIALS AND METHODS}

We included 50 pre-eclamptic women for this descriptive comparative study. For controls, 20 healthy pregnant women were selected. Sample size was selected conveniently. Immediately after delivery, maternal and cord blood samples were collected from all the participants, and after serum separation estimation of serum lipid profile and MDA were performed. The results were compared.

\section{RESULTS}

We observed a direct relationship between serum triglycerides and MDA in patients with pre-eclampsia. Hypertriglyceridaemia and high MDA level have been observed in pre-eclampsia.

\section{CONCLUSION}

Altered lipid profile may be responsible for increased oxidative stress that results due to increased lipid peroxidation in preeclampsia and this might be responsible for other complications during pregnancy.

\section{KEYWORDS}

Pre-eclampsia, Oxidative Stress, Lipid Peroxidation, Maternal Blood, Cord Blood, Lipid Profile, MDA.

HOW TO CITE THIS ARTICLE: Kumari R, Kumar G, Chhetri N, et al. Oxidative stress in pre-eclampsia- a study on correlation between malondialdehyde and lipid profile from maternal and cord blood. J. Evolution Med. Dent. Sci. 2017;6(82):5755-5758, DOI: $10.14260 /$ jemds $/ 2017 / 1248$

\section{BACKGROUND \\ Pre-eclampsia affects between $0.4 \%$ and $2.8 \%$ of all pregnancies in developed countries and more in developing countries, leading to as many as $83,70,000$ cases worldwide per year. ${ }^{1}$ The disorder is more prevalent in first pregnancy and is considered to be one of the important complications of pregnancy, and mostly associated with maternal and foetal morbidity and mortality. In developing countries, more than $90 \%$ of the subjects are affected with life-threatening outcomes of the disorder. ${ }^{1}$}

'Financial or Other Competing Interest': None.

Submission 15-07-2017, Peer Review 30-09-2017,

Acceptance 06-10-2017, Published 12-10-2017.

Corresponding Author:

Dr. Gorachand Bhattacharya,

57/2, Shyamnagar Road,

Kolkata-700055.

E-mail: drgbhattacharya@gmail.com

DOI: $10.14260 /$ jemds $/ 2017 / 1248$
According to the International Society of the Study of Hypertension in Pregnancy, pregnancy-induced hypertension (PIH) is considered when the blood pressure is $140 / 90$ or more and that has been measured on two separate occasions with an interval of more than six hours without proteinuria and occurring after 20th week of gestation. Pre-eclampsia is PIH with proteinuria manifested by either $\geq 300 \mathrm{mg}$ protein excreted per day or a urinary protein/ creatinine ratio $\geq 30$ $\mathrm{mg} / \mathrm{mmol} .^{2}$ Pre-eclampsia has been recognised as a multisystem disorder and may affect brain, lungs, kidney and liver. The risk of pre-eclampsia markedly increases in women who developed pre-eclampsia in previous pregnancies and in women who had either pre-existing vascular disease or conditions associated with increased cardiovascular risk, renal disease, hypertension, diabetes, thrombophilia and obesity (body mass index > 29). ${ }^{3}$ Women having symptoms of pre-eclampsia are also at greater risk for cardiovascular disease in later life, 4,5 and since pregnancy itself is considered as a transient state of metabolic syndrome this may represent as a stress state that unmasks latent cardiovascular risk 
factors. ${ }^{6}$ The cause of pre-eclampsia remains still unknown but poor placentation is an important predisposing factor. ${ }^{7}$ Although, there is clearly a focal role for placental dysfunction in pre-eclampsia, a number of theories have been proposed to explain this disorder. ${ }^{8}$ This has been reported by researchers that enhanced generation of placental superoxide free radicals results in oxidative stress. ${ }^{9}$

Among the various effects of oxygen-free radicals, initiation of membrane lipid peroxidation, oxidative damage to biomolecules and cellular dysfunction are the common factors that might initiate maternal vascular endothelial dysfunction and leukocyte activation. In pregnancies affected with pre-eclampsia during the process of placental development, failure of spiral artery remodelling in the placental bed was first observed by Brosens et $\mathrm{al}^{10}$ and the failure was associated with partial inability of placental trophoblast invasion. ${ }^{11}$ These observations support the cause of adversity of pre-eclampsia. It has been reported that in pregnancy of 10 to 12 weeks' gestation, the onset of maternal blood flow in the placenta results in a local increase in oxygen tension with simultaneous increase in expression and activity of several antioxidant enzymes. ${ }^{12}$

Frequent thrombotic occlusion followed by clot dissolution might lead to repeated hypoxia/re-oxygenation insult in the affected placenta throughout pregnancy. This is thought to be a potent stimulus for the activation of Xanthine Oxidase, which is an important source for generation of superoxide free radicals and this takes place in abundance in cytotrophoblast, syncytiotrophoblast and villous stromal cells. ${ }^{13}$ Study on placental tissue from women with preeclampsia confirms enhanced expression and activity of this enzyme. ${ }^{14}$ Xanthine oxidase is thought to play a fundamental role in free radical induced tissue damage in human placenta and as a result of under-perfusion, necrotic processes could lead to discharge syncytiotrophoblast microvesicles into maternal circulation. These microparticles present in the blood during pregnancy have been shown to increase in concentration in pre-eclampsia and have been directly involved in activation of maternal neutrophils, which in turn might contribute to activation of the vascular endothelium. ${ }^{14}$ NAD(P)H oxidases are a major source of superoxide free radicals in neutrophils and vascular endothelial cells of human trophoblast. 15 Considering the involvement of xanthine oxidase and $\mathrm{NAD}(\mathrm{P}) \mathrm{H}$ oxidase, researchers proposed that placental tissue of women with pre-eclampsia produces excess superoxide free radicals. ${ }^{16,17,18}$ Placental oxidative stress may directly or indirectly lead to oxidative stress in the maternal circulation. Free radical generation may induce shedding of placental "debris" and in vitro evidence suggests that syncytiotrophoblast microvesicles may lead to activation of maternal neutrophils. ${ }^{19}$

\section{Aim and Objective}

The aim of the study was to assess lipid profile and oxidative stress in pre-eclampsia with specific objective to compare serum levels of lipid peroxidation products like TBARS in cord and maternal blood samples of subjects of pre-eclampsia in order to establish a correlation between lipid profile parameters and lipid peroxidation product in pre-eclampsia.

\section{MATERIALS AND METHODS}

\section{Study Design}

A descriptive comparative study. Blood samples were collected in plain vials from all participants just after delivery with simultaneous collection of cord blood samples. After separation of serum, this was used for estimation of lipid profile and malondialdehyde. Analytical parameters were measured by standardised photometric methods.

\section{Sample Size}

Sample size was taken conveniently. In this study, we included 50 women with pre-eclampsia; 20 pregnant women who were otherwise healthy and not presenting with preeclampsia were selected as controls.

Present study was conducted in the Department of Biochemistry, MGM Medical College and LSK Hospital, Kishanganj, Bihar, India. The study was undertaken to determine the changes in lipid profile and oxidative stress parameters in cord and maternal blood of 50 pre-eclamptic women during delivery. The results were compared with the results of 20 healthy pregnant women. Demographic and clinical data were collected at routine obstetric visits. Blood samples were obtained by venous puncture from the antecubital vein of mothers and simultaneously cord blood was collected in plain vials. Informed consent was obtained from all participants prior to initiation of the study. Ethical clearance was obtained from Institutional Ethical Committee. Serum was separated and analysed for lipid profile by using standard methods. MDA estimation has been performed by Thiobarbituric Acid (TBA) reaction.

\section{Principle of the Method}

Malondialdehyde (MDA) forms a 1:2 adduct with thiobarbituric acid that is measured by spectrophotometry.

Biological specimens contain a mixture of Thiobarbituric Acid Reactive Substances (TBARS) including Lipid hydroperoxides and aldehydes, and these are increased in concentration as a result of oxidative stress.

In practice, TBARS are expressed in terms of malondialdehyde (MDA) equivalents. ${ }^{20}$ In this assay, 1,1,3,3tetraethyl propane had been used as MDA standard in various dilutions and a standard curve was prepared and unknown samples were plotted accordingly.

The results were compared with control group for statistical analysis. Data was analysed in SPSS version 20.0 software. Value of individual parameters was expressed as Mean \pm Standard deviation. Significance of differences of the Means within groups was tested by Student ' $\mathrm{t}$ ' test and $\mathrm{p}$ value of less than 0.05 was considered to be statistically significant.

\section{RESULTS}

\begin{tabular}{|c|c|c|c|}
\hline Parameter & $\begin{array}{c}\text { Control } \\
(\mathbf{n = 2 0 )}\end{array}$ & $\begin{array}{c}\text { Pre- } \\
\text { eclampsia } \\
(\mathbf{n = 5 0})\end{array}$ & P value \\
\hline BP (Systolic) $\mathrm{mmHg}$ & $114 \pm 8$ & $156 \pm 14$ & $<0.001$ \\
\hline BP (Diastolic) $\mathrm{mmHg}$ & $74 \pm 6.5$ & $96 \pm 8.5$ & $<0.001$ \\
\hline \multicolumn{4}{|c|}{ Table 1. Distribution of Blood } \\
Pressure among Test and Control Group \\
\hline
\end{tabular}

\begin{tabular}{|c|c|c|}
\hline Age in Years & Control (n = 20) & Pre-eclampsia (n = 50) \\
\hline $15-20$ & 4 & 13 \\
\hline $21-25$ & 10 & 29 \\
\hline $26-30$ & 6 & 08 \\
\hline \multicolumn{3}{|c|}{ Table 2. Distribution of Age } \\
\hline
\end{tabular}




\begin{tabular}{|c|c|c|}
\hline Gravida & $\begin{array}{l}\text { Control } \\
(n=20)\end{array}$ & $\begin{array}{l}\text { Pre-eclampsia } \\
\quad(n=50)\end{array}$ \\
\hline Primi gravida (G1) & 15 & 27 \\
\hline Second gravida (G2) & 5 & 16 \\
\hline Third gravida (G3) & -- & 07 \\
\hline \multicolumn{3}{|c|}{ Table 3. Distribution of Gravida } \\
\hline
\end{tabular}

\begin{tabular}{|c|c|c|c|}
\hline Parameters & $\begin{array}{l}\text { Control } \\
(n=20)\end{array}$ & $\begin{array}{c}\text { Pre- } \\
\text { eclampsia } \\
(n=50)\end{array}$ & $P$ value \\
\hline $\begin{array}{l}\text { Triglycerides } \\
\text { (mg/dL) }\end{array}$ & $153 \pm 11$ & $259 \pm 32$ & $<0.001$ \\
\hline $\begin{array}{c}\text { Total Cholesterol } \\
(\mathrm{mg} / \mathrm{dL})\end{array}$ & $202 \pm 19$ & $247 \pm 13$ & $<0.001$ \\
\hline $\begin{array}{l}\text { HDL Cholesterol } \\
\text { in }(\mathrm{mg} / \mathrm{dL})\end{array}$ & $49 \pm 3.4$ & $47 \pm 5$ & $<0.001$ \\
\hline $\begin{array}{l}\text { LDL Cholesterol } \\
\text { in }(\mathrm{mg} / \mathrm{dL})\end{array}$ & $123 \pm 20$ & $148 \pm 11$ & $<0.001$ \\
\hline $\begin{array}{l}\text { VLDL Cholesterol } \\
\text { (mg/dL) }\end{array}$ & $30 \pm 2.3$ & $52 \pm 6.4$ & $<0.001$ \\
\hline MDA (nmol/dL) & $3.85 \pm 0.31$ & $7.55 \pm 0.43$ & $<0.005$ \\
\hline
\end{tabular}

Table 4. Biochemical Parameters in Maternal Blood of Control and Pre-eclampsia Subjects (Mean \pm SD)

\begin{tabular}{|c|c|c|c|}
\hline $\begin{array}{c}\text { Parameters } \\
\text { (mg/dL) }\end{array}$ & $\begin{array}{c}\text { Control } \\
(\mathbf{n = 2 0 )}\end{array}$ & $\begin{array}{c}\text { Pre- } \\
\text { eclampsia } \\
(\mathbf{n}=\mathbf{5 0})\end{array}$ & P value \\
\hline Triglycerides & $64 \pm 8$ & $89 \pm 4$ & $<0.001$ \\
\hline Total Cholesterol & $171 \pm 8$ & $177 \pm 4$ & $\mathrm{NS}$ \\
\hline HDL Cholesterol & $41 \pm 4.4$ & $39 \pm 2$ & $<0.005$ \\
\hline LDL Cholesterol & $118 \pm 9$ & $120 \pm 3$ & $\mathrm{NS}$ \\
\hline VLDL Cholesterol & $13 \pm 2$ & $18 \pm 0.8$ & $<0.001$ \\
\hline MDA (nmol/dL) & $3.97 \pm 0.36$ & $6.6 \pm 0.31$ & $<0.005$ \\
\hline \multicolumn{4}{|c|}{ Table 5. Biochemical Parameters in Cord Blood of } \\
Controls and Pre-eclampsia Subjects (Mean \pm SD) \\
\hline
\end{tabular}

\section{DISCUSSION}

Altered lipid profile in women with pre-eclampsia may be a predisposing factor for oxidative stress. Meis $\mathrm{P}$ et al observed in their study that serum free fatty acids, triglycerides and very low-density Lipoprotein cholesterol (VLDLc) concentrations were elevated, whereas concentrations of cholesterol, lipoprotein (a) and the other lipoproteins ${ }^{21}$ remain unaltered in subjects of pre-eclampsia. Roberts $J$ and Hubel et al in two separate studies proposed that the lowdensity lipoprotein cholesterol (LDLc) particles were smaller than those of normotensive controls and that may facilitate their oxidation. ${ }^{22,23}$ One of the biomarkers of lipid peroxidation found to be elevated early in the plasma of women with pre-eclampsia is malondialdehyde (MDA), which is a major metabolite of lipid peroxide breakdown. ${ }^{24}$

A number of relevant assays including Thiobarbituric acid reactive substances, conjugated dienes, $\mathrm{F}_{2}$-isoprostanes (usually 8-epi-prostaglandin $\mathrm{F}_{2} \propto$ ), and antibodies against oxidatively modified low-density lipoprotein have been studied extensively.7,9

Vanderlelie et al described higher serum MDA concentrations in women with pre-eclampsia. They observed a higher MDA/ total antioxidant ratio in women with preeclampsia and this is considered to be a potent indicator of oxidative stress. $^{25}$
Our observations were similar to their findings. Our study indicates serum malondialdehyde levels of both cord and maternal blood for pre-eclampsia cases were elevated as compared to controls ( $\mathrm{p}$ value $<0.001$ ). This may be due to increased production of placental lipid peroxides. Lipid peroxidation results in generation of primary lipid peroxidation products such as lipid hydroperoxides and secondary products like malondialdehyde and lipid peroxides.

Plasma triglycerides levels in cord and maternal blood of pre-eclamptic subjects was significantly higher than the control values ( $p<0.001)$. Plasma total cholesterol levels in cord blood did not show any significant difference, whereas in maternal blood a significant increase had been observed in pre-eclampsia cases as compared to control group ( $\mathrm{p}<$ 0.001). LDL and VLDL cholesterol levels in pre-eclampsia were increased significantly, $(\mathrm{p}<0.001)$ and $(\mathrm{p}<0.001)$. This observation suggests that in pre-eclampsia, there might be significant decrease in the hydrolysis of triglycerides when compared to normal gestation and that results impaired generation of LDL particles from triglycerides rich lipoproteins.

\section{CONCLUSION}

The study indicates a direct relationship between serum triglycerides and malondialdehyde concentration in preeclampsia patient and altered lipid profile due to increased serum triglycerides level might be a predisposing factor for pre-eclampsia.

\section{ACKNOWLEDGEMENTS}

The authors wish to acknowledge Dr. DK Jaiswal, Director of the Institute and Dr. Pranati Gupta, HOD G and O for their continuous support and valuable suggestions throughout the study period.

\section{Ethical Approval}

All procedures performed in the study involving human participants were according to the ethical standard of Institutional and/or National Research Committee and with the 1964 Helsinki declaration and its later amendments or comparable ethical standards.

\section{REFERENCES}

[1] Villar K, Say L, Gülmezoglu AM, et al. Eclampsia and pre-eclampsia: a health problem for 2000 years. In: Critchley H, MacLean AB, Poston L, Walker JJ, eds. Preeclampsia. London: RCOG Press 2003:189-207.

[2] Brown MA, Lindheimer MD, de Swiet M, et al. The classification and diagnosis of the hypertensive disorders of pregnancy: statement from the International Society for the Study of Hypertension in Pregnancy (ISSHP). Hypertens Pregnancy 2001;20(1):9-15.

[3] Plummer S, Morgan L. Is pre-eclampsia an inherited disorder? In: Critchley H, MacLean AB, Poston L, et al, eds. Pre-eclampsia. London: RCOG Press 2003:225-35.

[4] Irgens HU, Reisaeter L, Irgens LM, et al. Long term mortality of mothers and fathers after pre-eclampsia: population based cohort study. BMJ 2001;323(7323):1213-7. 
[5] Sattar N, Greer IA. Pregnancy complications and maternal cardiovascular risk: opportunities for intervention and screening. BMJ 2002;325(7356):15760.

[6] Roberts JM, Hubel CA. Is oxidative stress the link in the two-stage model of pre-eclampsia? Lancet 1999;354(9181):788-9.

[7] Redman CW, Sargent IL. Placental debris, oxidative stress and pre-eclampsia. Placenta 2000;21(7):597602.

[8] Hubel CA. Oxidative stress in the pathogenesis of preeclampsia. Proc Soc Exp Biol Med 1999;222(3):222-35.

[9] Redman CW, Sargent IL. Pre-eclampsia, the placenta and the maternal systemic inflammatory response -a review. Placenta 2003;24: S21-7.

[10] Brosens IA, Robertson WB, Dixon HG. The role of the spiral arteries in the pathogenesis of preeclampsia. Obstet Gynecol Annu 1972;1:177-91.

[11] Pijnenborg R, Anthony J, Davey DA, et al. Placental bed spiral arteries in the hypertensive disorders of pregnancy. Br J Obstet Gynaecol 1991;98(7):648-55.

[12] Levine RJ, Maynard SE, Qian C, et al. Circulating angiogenic factors and the risk of preeclampsia. $\mathrm{N}$ Engl J Med 2004;350(7):672-83.

[13] Jauniaux E, Watson AL, Hempstock J, et al. Onset of maternal arterial blood flow and placental oxidative stress. A possible factor in human early pregnancy failure. Am J Pathol 2000;157(6):2111-22.

[14] Many A, Hubel CA, Fisher SJ, et al. Invasive cytotrophoblasts manifest evidence of oxidative stress in preeclampsia. Am J Pathol 2000;156(1):321-31.

[15] Griendling KK, Sorescu D, Ushio-Fukai M. NAD(P)H oxidase: role in cardiovascular biology and disease. Circ Res 2000;86(5):494-501.

[16] Manes C. Human placental NAD(P)H oxidase: solubilization and properties. Placenta 2001;22(1):5863.
[17] Lee VM, Quinn PA, Jennings SC, et al. Neutrophil activation and production of reactive oxygen species in pre-eclampsia. J Hypertens 2003;21(2):395-402.

[18] Lef'evre G, Beljean-Leymarie $M$, Beyerle $F$, et al. Evaluation of lipid peroxidation by measuring TBRS. Annals de Biologie Clinique 1998;56(3):305-19.

[19] Meis PJ, Goldenberg R, Mercer BM. The preterm prediction study: risk factors for indicated preterm births. Maternal-Fetal Medicine Units Network of the National Institute of Child Health and Human Development. Am J Obstet Gynecol 1998;178(3):5627.

[20] Knopp RH, Bonet B, Lasuncion MA, et al. Lipoprotein metabolism in pregnancy. In: Herrera E, Knopp R, eds. Perinatal biochemistry. Boca Raton, FL: CRC Press Inc 1992:20-51.

[21] Roberts J. Pregnancy-related hypertension. In: Creasy R, Resnik R, eds. Maternal fetal medicine. Philadelphia: WB Saunders 1994:804-43.

[22] Roberts JM. Endothelial dysfunction in preeclampsia. Semin Reprod Endocrinol 1998;16(1):5-15.

[23] Hubel CA, Shakir Y, Gallaher MJ, et al. Low-density lipoprotein particle size decreases during normal pregnancy in association with triglyceride increases. J Soc Gynecol Invest 1998;5(5):244-50.

[24] Hubel CA, McLaughlin MK, Evans RW, et al. Fasting serum triglycerides, free fatty acids, and malondialdehyde are increased in preeclampsia, are positively correlated, and decrease within 48 hours postpartum. Am J Obstet Gynecol 1996;174:975-82.

[25] Vanderlelie J, Venardos K, Clifton VL, et al. Increased biological oxidation and reduced anti-oxidant enzyme activity in pre-eclamptic placentae. Placenta 2004;26(1):53-8. 